Article

\title{
Desired but Neglected: Investigating the Consideration of Alternatives in Austrian EIA and SEA Practice
}

\author{
Alexandra Jiricka-Pürrer ${ }^{1, *}$, Martin Bösch ${ }^{2,+}$ and Ulrike Pröbstl-Haider ${ }^{1}$ \\ 1 Department of Landscape, Spatial and Infrastructure Sciences, University of Natural Resources and Life \\ Sciences, Peter-Jordan Street 82, A-1190 Vienna, Austria; ulrike.proebstl@boku.ac.at \\ 2 Natura 2000 Management, Federal State Vorarlberg, Inatura, Jahngasse 9A-6850 Dornbirn, Austria; \\ martin.boesch@naturvielfalt.at \\ * Correspondence: Alexandra.jiricka@boku.ac.at; Tel.: +43-1-47654-85323 \\ + Former staff of the ministry of the environment BNT/BMFLUW-in times of data collection.
}

Received: 3 August 2018; Accepted: 4 October 2018; Published: 14 October 2018

\begin{abstract}
Although the consideration of alternatives is seen as a core element of impact assessments (IA) such as environmental impact assessments (EIAs) and strategic environmental assessments (SEAs), there are few scientific papers that have addressed this topic in depth based on a large empirical study. These studies, as well as the last evaluation of the application of the SEA Directive by the EC, have concluded that there is need for improvement regarding the consideration of alternatives. This paper presents a large quantitative appraisal of the consideration of alternatives in current EIA and SEA practice in Austria. Through a criteria-based evaluation of 100 environmental impact statements (EIAs) and 71 environmental reports (SEA), a quantitative and partly qualitative review was undertaken. The criteria embrace the aspects of "types of alternatives", "combination of alternatives", "environmental relevance", "presentation/structure", as well as the "consideration of the zero-alternative". The deficiencies that were identified empirically point out the need for improvement. In particular, a strong need for improvement was identified for both instruments regarding the low environmental relevance of the alternative assessment that was presented, as well as the lack of linking the zero variant to the future development of the environmental issues.
\end{abstract}

Keywords: consideration of alternatives; zero variant; EIA; SEA

\section{Introduction}

The two instruments, the environmental impact assessment (EIA) at the project level and the strategic environmental assessment (SEA) at the plan and programme level, are perceived as key components of sustainable development planning [1-3]. In this context, the consideration of reasonable and feasible alternatives to achieve environmental objectives and balance them with other objectives (e.g., social or health-oriented ones) plays a crucial role. The presentation and evaluation of alternatives is perceived as a precondition for transparent decision making and the selection of solutions, which are less harmful for the environment or human health $[4,5]$. Therefore, the consideration of reasonable alternatives is a key evaluation criterion that has been used in many international evaluations of performances of EIA and SEA systems (e.g., see [6-11]).

Although the consideration of alternatives is seen as one core element of environmental impact assessments [12-15], there are few scientific papers addressing this topic in depth. Studies have already shown great deficits in the consideration of alternatives $[9,11,16]$. In addition, clear classifications and definitions about alternatives, reasonable alternatives, alternative means, and the so-called "zero alternative" are often missing [17], and critically discussed [18,19]. Several authors [10,20,21] 
also highlight the likely changes in the types of alternatives selected on the EIA level due to the consideration of "strategic" alternatives at the SEA level. Strong differences in the consideration of alternatives are of course also related to the conceptualization of the two instruments $[12,22,23]$ as well as the level (and detail) of the plan/programme or project application documents.

During the course of the amendment to the EIA Directive 2014/52/EU [24], the important role of the consideration of alternatives in the EIA process was again emphasised. Compared to the final version of the amended EIA Directive, the proposal of the commission for a directive (COM/2012/0628 final) amending Directive 2011/92/EU [24] on the assessment of the effects of certain public and private projects on the environment would have envisaged an even greater strengthening of the consideration of alternatives [25]. The current technical discussion on the implementation of the newly amended EIA Directive 2014/52/EU takes up this aspect [19,26-28]. In the report [29] of the 10 years of the SEA Directive [30] - as part of the reporting process envisaged under article 12 of the SEA Directive- the revisers also conclude that there is need for improvement regarding the consideration of alternatives.

An appraisal of the consideration of alternatives in current EIA and SEA practice is therefore of great interest. Based on a representative number of EIA and SEA procedures in Austria, this study aims to:

- examine the current consideration of alternatives in the EIA and SEA processes in Austria,

- evaluate the performance against contextual factors and the respective EIA and SEA practices and finally,

- discuss possible improvements to the planning processes.

The results of this study are presented in Section 4. Section 3 explains the qualitative methodological approach, following a theoretical overview of the issue of consideration of alternatives in the international scientific literature in Section 2. Section 5 discusses the results against the international literature and the specific challenges of the Austrian system. Finally, in Section 6, future research topics for an in-depth analysis are outlined.

\section{Background}

While the consideration of alternatives has been an issue for research and many international comparisons of EIA processes for several decades [14,31,32], the literature on alternatives in SEA processes is less developed [12,29]. For the EIA, Steinemann [33] stated that a decision is always a choice of one or more options, with the quality of the choice depending directly on the quality of the possible alternatives. He also argued that the EIA must provide authorities with the environmental information that is necessary to protect, restore, or improve the environment. In this respect, the argument for the consideration of alternatives follows the precautionary principle, as specified amongst others by Tickner and Geiser [34]. The presentation of alternatives in the environmental report or in the environmental impact statement (EIS) should guarantee a certain transparency of the preceding planning process, and should allow for further optimisation [35,36]. Other authors have underlined the participatory component of alternatives. Phylip-Jones and Fischer [10] used for their EIA criteria scoring system the following two statements to describe an optimal consideration of alternatives in EIA processes: "All concerned stakeholders had the opportunity to provide their opinions on the alternatives set out", and "the assessment of alternatives led to the most environmentally, sustainable option being selected". Overall, it can be summarised that best practise depends on the degree of enabled process transparency on one hand, and on the possibilities to question and discuss the planning and project preparation in a critical and participatory manner on the other. The discussion about the extent, presentation, and definition of alternatives is a crucial step, in this regard, towards providing information for decision making [16,32].

Overall, the literature review reveals that the consideration of alternatives in the SEA process could be complemental to EIA. It is perceived as a crucial step during the course of SEA that is related to the preparation of a basis for decision [29]. According to Callies and Dross [37], as well as 
Rehausen et al. [15], the consideration of alternatives has even been highlighted as a "characterising feature" of the SEA. Geißler and Rehhausen [38] pointed out that this "key phase", above all, ensures the strategic orientation of the instrument due to an increased flexibility at the planning level in comparison to the subsequent project level. Thereby the SEA is-according to the planning level and scope of the plan/programme-providing a comprehensive basis for a strategic decision [12,17]. Differences in the aim and leeway when considering alternatives, are of course attributed to the diverse conceptual approaches of SEAs, which are again influenced by the conditions under which SEAs are carried out as well as the planning level and purpose.

Fischer and Gazzola [39] highlighted the participatory component of alternatives and its relevance for SEA effectiveness. Again, however, strong differences could be observed in the interest in participating in the consideration of alternatives by the public according to the planning context and scope $[13,40]$. In the case of the SEA, especially, the consideration of alternatives needs to be seen in relation to the objectives of the plan/programme as well as in relation to other superordinate objectives concerning the environmental issues in the environmental assessment $[15,29,41]$. The possible options are oriented towards specific objectives, which ultimately determine the decision. The formulation of objectives, above all, and the inclusion of environmental objectives in the consideration process are central for the type and expression of alternatives. Objectives can be concretised and organised hierarchically into objectives and sub-objectives [12]. Depending on the degree of specification of an objective, the possible scope for decision making in order to achieve the objective is either limited or expanded, thereby drawing the radius for the search for alternatives [42].

Overall, despite the different approach of EIA and SEA processes, it seems that for the consideration of alternatives, generally speaking, its relevance is recognized similarly for both instruments.

\subsection{Definitions}

Related to the actual fulfilment of the objectives of the project (EIA) or plan or programme (SEA), there can be various alternatives and combinations of types of alternatives depending on the scope of the EIA/SEA as well as on the results of superordinate environmental assessments consulted for the tiering. Gonzalez et al. [43] differentiated several approaches to the development of alternatives, ranging from "strategic" to "modal". Furthermore, the guidance on the generation of alternatives in SEA mentions also the "temporal" aspect as one possible approach. Overall, the literature is characterized by various terms around "alternatives", including "alternative means of achieving objectives", "technical alternatives, "concept alternatives", "procedural alternatives", "execution alternatives", or "reasonable alternatives" (see below). In the following, the common understanding of these different terms in the context of EIA and SEA are described and distinguished from other crucial terms in this context such as mitigation.

The understanding of an alternative differs in the context of EIA and SEA, but also in its understanding and implementation in the respective practise. An exceptional type of "alternative" is the "zero variant" or "zero alternative", which actually provides the "reference framework for the evaluation" [41] (p. 45), thereby not constituting an actual alternative to the proposal, but a reference for evaluation [11,27,31,33]. Therefore the "do-nothing or zero alternative" [29] can be perceived as the minimum requirement for both EIA and SEA. This understanding has been confirmed for all of the European Union (EU) member states with Directive 2014/52/EU. According to recital 31 and its Annex IV Z 3, an EIA report must include "a description of the relevant aspects of the current state of the environment (baseline scenario) and an outline of the likely evolution thereof without implementation of the project as far as natural changes from the baseline scenario can be assessed with reasonable effort on the basis of the availability of environmental information and scientific knowledge." In Austria, the so-called zero-alternative is often discussed firsthand, comparing the planned situation with the development without the plan/programme or project. The actual relevance of the zero-alternative is most apparent 
in the SEA Directive, which seeks to provide alternative courses of action and where the prognosis of continuation/cessation of a plan/programme is crucial for the further development of a strategy.

Apart from the zero variant, several types of "real" alternatives are discussed in the literature. First of all, the term "technical alternatives" is often used $[17,29,44]$. These alternatives consider the implementation level (construction and operation) of the project (or plan/programme), and provide different feasible technical solutions. The principle idea of the project or plan, the "basic concept" itself and/or objectives [45], are not overthrown by this form of alternatives. Other terms are used synonymously in the literature for this type of alternative, such as "execution alternatives", "alternative methods" [46] (p. 80), "technical procedural alternatives" [45] (p. 116), or "technological alternatives" [47] (p. 47). However, these terms often fall short and are misleading, because these alternatives embrace technical (pollution filters, noise barriers) and non-technical measures (operation times, logistics management, visitor direction management, etc.) that belong to the group of mitigation measures rather than alternatives. Thus, it is often difficult to distinguish in Austrian practice between a so-called technical alternative and the definition of a mitigation measure. For this reason, some national guidelines such as Busse et al. [3] explained and defined the differences between alternatives, mitigation, and compensation measures to avoid misinterpretation and misunderstanding. Most important to characterise measures is the direct link to mitigate or compensate specific negative impacts on certain environmental issues identified in the impact assessment, whereas alternatives are timely considered before this step.

Alternatives might also be proposed by stakeholders and the involved public usually during the screening or scoping phase of an EIA or SEA $[48,49]$. Suggestions by stakeholders often comprise a wide range of proposed alternatives from small modifications of the project or plan to new solutions for achieving the desired objective. The proposed modifications often focus on locational alternatives [45] (p. 117). This discussion is closely related to the process of scoping-the identification of the relevant assessment area and methodological approach in order to assess significant impacts by the project/plan/programme on environmental issues-since the extent of impacts is also determined by the site of the project (European Commission 2001, Pt. A1/B.4.2, Checklist of potential alternatives and mitigation measures [50]).

The literature and guidelines repeatedly point to the possibility of adjusting the project dimension [29]. Thus, the size or extension of the project is questioned, since the extent of impacts is also determined by these criteria (European Commission 2001, Pt. A1/B.4.2, Checklist of potential alternatives and mitigation measures [50]). A specific term for such alternatives has not yet emerged. They will be termed "dimension alternatives" [29] here for the sake of completeness. They refer to adaptation of the plan/programme or project on the one hand, and to dimension modifications within the projects (such as frequency or intensity of intended use, production volume, etc.) on the other.

If one compares alternatives according to their degree of freedom of decision in achieving desired objectives, concept alternatives offer the greatest freedom of decision. In the case of a "concept alternative", the objective itself, or the objective level, are up for discussion. In this case, higher or lower objective levels may also be considered [42]. Friedrichsen [45] (p. 114) also spoke of "objective alternatives". The fulfilment of an objective is thereby not sought within a solution pathway of the same hierarchical level, but rather strategically within the entire system. For this reason, some authors (e.g., $[17,29])$ also term this the "system alternatives" or "strategic alternatives". Gonzalez et al. [43] further suggested integrating temporally dynamic scenarios of alternatives in strategic planning, as has already been recommended in a European Commission guideline, since alternative scenarios need to be considered as possible alternatives in the case of long-term plans and programmes, especially "for the very distant future" [51] (p. 30). Concept alternatives generally demand abandoning or even going beyond the respective target system, or questioning the original means of achieving the objective entirely [52]. Thereby, the concept alternative is more of a change of strategy compared to the project or plan: "Strategic alternatives: different ways of achieving the objective of the plan or programme without disproportionate costs or exceptional technical problems" [29] (p. 112). "System alternatives" following a 
further reaching approach are those considering potential questions of demand — "need/demand"—as defined by Stoeglehner [17].

In those cases where the SEA and the EIA are both required (e.g., SEA on wind farms on a regional level followed by an EIA for the local project), the character of the alternatives on the EIA level has-theoretically and in some cases practically—changed. While the strategic discussion of various locations has been done in the SEA, the EIA focusses now on dimension or technical alternatives only $[3,10]$. In this case in particular, the "alternatives hierarchy" becomes relevant [53].

Tiering with regard to the consideration of alternatives will be more important in the future in Austria. The legal implementation of the SEA Directive took place with delay for some matters $[54,55]$ and plans/programmes are revised only after larger periods of times (e.g., 10 or 15 years), which means that an application of both instruments as intended by the EU Directives occurred only recently. Therefore, so far, tiering can be considered when evaluating both SEA and EIA processes only to a limited extent.

Detailed background information on specifications of the Austrian EIA and SEA system-with regard to the consideration of alternatives-are provided in the next sub-section.

\subsection{Specification of Alternatives in the EIA and SEA Processes in Austria}

Although theoretically the purpose of the consideration of alternatives is comparable internationally [56], the specifications of the national planning system and legal requirements play a crucial role in practice [32]. In Austria, the EIA as a strongly project-related procedure, focusses on the presentation of alternatives rather than on their development. It is defined by federal law and steered by federal guidance documents (e.g., [47]), and entirely embedded in a facility-specific legal approval procedure [57]. Due to the concrete commissioning level, it is sometimes difficult to distinguish between a so-called technical alternative and the definition of a mitigation measure.

The consideration of alternatives within the framework of the Austrian EIA is substantially predefined by the project applicant. In line with the requirement for optimisation, the project applicant develops project-immanent alternatives in Austria, so that a project can be submitted with lower environmental impacts. Thereby, a mere presentation of alternatives is demanded of the project applicant within the framework of the environmental report [58], without any mandatory requirement [59].

However, the SEA is characterized by a great variety of legal implementations that result also in a very different quality of applications in Austria. The current practice includes both the consideration of very limited spatial alternatives as well as very concept-oriented, far-reaching provisions for incorporating planning alternatives. However, a wide scope of potential alternatives can affect their degree of detail [60]. The strategically oriented width of the planning level tends to come at the expense of depth, depending on the level of planning hierarchy (the scope) on which the plan or programme requiring assessment is positioned. Accordingly, the consideration of alternatives is partly postponed to the project level. At the same time, the limited application of SEA at strategic planning levels (e.g., at regional programmes in the context of spatial planning) limits the options for considering conceptual alternatives. Finally, the outcome of the SEA is not legally binding. Therefore, alternatives are primarily expressed in the environmental report rather than in the actual decision-making process. As explained above, Austrian EIA practice has little experience with tiering between plan/programme-level alternatives and project-level alternatives. If at all, EIA and SEA have been carried out in parallel in the due to the (partly) delayed implementation of the SEA Directive. EIA projects take quite a long time for elaboration and assessment in Austria, and therefore, in most of the cases that were analysed in this study, no SEA was available at the beginning of the EIA procedure.

To sum up, the consideration of alternatives is a mandatory element of the environmental evaluation procedure in both directives (EIA and SEA); the Austrian guidelines and applications include this aspect. However, an extensive observance of alternatives-as demanded in the literature-is currently not a criterion for approval. Pursuant to the critical discussion regarding 
the different functions and effects of the consideration of alternatives in both instruments, there is a necessity to analyse the current practice in detail. According to past expert-based studies, one could conclude that in most cases, the consideration of alternatives exists only in rudimentary or partial form $[17,56]$.

\subsection{Research Objectives}

Since there are only a few comprehensive, empirical, and scientific studies on the consideration of alternatives to date, the present study aims to make a contribution toward objectifying the discussion on this very important partial step of both environmental assessment procedures by analysing a large sample of EIA and SEA cases. The study will analyse:

- the number of examined alternatives and the types of alternatives considered in EIA and SEA reports,

- the reference made to the project and planning environment during the course of the consideration of alternatives,

- the transparency and presentation of alternatives in the written description,

- the consideration of the zero-alternative in EIA and SEA, and finally

- the differences in the application practise between EIA and SEA in Austria.

\section{Methodological Approach}

The analysis of EIA and SEA case studies from Austria were carried out by a small project team with expertise in planning and law. Whereas previous studies on the effectiveness of EIA and SEA as well as certain aspects of each of them often combined a detailed analysis of a smaller number of documents combined with evidence from the feedback of planning practitioners (e.g., interviews), the purpose of this study was to gain a broad overview about the situation in Austria by reviewing a large number of EIA and SEA case studies. Compared to other countries, SEA and in particular EIA is characterised by a large number of assessment documents, which are subject to the final project commissioning procedure (with around $1000 \mathrm{p}$ for a single EIA), and a low number of EIA per year $[53,61]$.

Further details of the survey design are explained in the following:

\subsection{Database and Description of Sample}

If the SEA or EIA processes include a proper discussion of alternatives, this discussion and evaluation will be included into the "environmental impact assessment report" (EIA, term introduced by Directive 2014/52/EU) or the "environmental report" (SEA, term introduced by Directive 2001/42/EC). In the following, we use the simplified term "environmental report" for both types of impact assessment in the following. This report summarises the information that was analysed in the environmental assessment procedures, and it is a basis for decision making. The purpose of an environmental report, according to numerous authors $[16,62,63]$, is to offer transparent information on the environmental impacts both of the chosen project/plan/programme as well as alternatives to it. Therefore, the methodological approach is based on the given information on alternatives in the environmental reports (the 2014 Directive introduces this wording also for EIA).

In Austria, the environmental reports for EIA are available in a publicly accessible database (EIA-Database www.umweltbundesamt.at/umweltschutz/uvpoesterreich/uvpdatenbank/) implemented by the Federal Environment Agency Austria and the Austrian Ministry of the Environment. All of the case studies of EIA were taken from this public database. 
A look into the EIA database resulted in 425 EIA procedures from the beginning of EIA law in Austria until December 2015 for 89 theoretically different facility types (classified as Z-numbers in Annex 1 of EIA Act 2000 [64]; several of them are sub-categories of the main types). In order to provide comparable results, the diversity of facility types was reduced to the following representative sectors (see Table 1, [61] (p. 17)), including single-site and linear projects:

- Linear infrastructure: highways; high-capacity routes for trains, state roads, and railways,

- Single-site infrastructure: ski runs and lifts; golf courses; quarries and open-cast mining; installations for hydroelectric energy production; wind energy installations.

Table 1. Environmental impact statement (EIS) according to type of facility (100 out of 191 reports from environmental impact assessment (EIA) for the selected facility types).

\begin{tabular}{cccc}
\hline Types of Facility Analysed, EIA & $\begin{array}{c}\text { Number of EIS } \\
\text { Analysed }\end{array}$ & $\begin{array}{c}\text { Allocation to Sectors } \\
\text { (Project Types) in the } \\
\text { EIA-Act 2000 }\end{array}$ & $\begin{array}{c}\text { Representativeness (Facility Type in } \\
\text { Relation to Sectors (Project Types) } \\
\text { in the EIA Database) }\end{array}$ \\
\hline Art. 23a Federal roads & $15(25 \%)$ & $\begin{array}{c}\text { Highways and } \\
\text { high-capacity routes }\end{array}$ & $31 \%(\mathrm{n}=48)$ \\
Art. 23b high-capacity routes & $15(11 \%)$ & & $48 \%(\mathrm{n}=22)$ \\
\hline Annex 1 Z 9/10 State roads & $10(12 \%)$ & Infrastructure & $41 \%=24)$ \\
Annex 1 Z 12 Ski areas & $5(5 \%)$ & Mining & (n $=10)$ \\
Annex 1 Z 17 Golf courses & $18(15 \%)$ & Hydropower & $44 \%(\mathrm{n}=28)$ \\
\hline Annex 1 Z 25 Mining & $11(13 \%)$ & $75 \%(\mathrm{n}=8)$ \\
Annex 1 Z 26 Mining & $6(4 \%)$ & $76 \%(\mathrm{n}=26)$ \\
Annex 1 Z 30 Hydropower & $20(14 \%)$ & & $(100 \%$ are 191 EIS) \\
\hline Total & $\mathbf{1 0 0 / 1 0 0 \%}$ &
\end{tabular}

Due to a missing SEA database in Austria, examples were retrieved from an SEA information portal implemented by the Federal Environment Agency Austria and the BMLFUW (SEA documentation with examples from www.strategischeumweltpruefung.at). In order to enhance the comparability of the findings from the EIA-related and the SEA-related assessment, the study included only SEA reports from the same sectors as the EIA projects pertained to (following $[17,65]$ ): plans/programmes from local (municipal) and supralocal spatial planning (regional) and from the transport sector. Very abstract SEA programmes and procedures (such as for European Territorial Cohesion Funding) were excluded, as they are limited in their consideration of alternatives and focus primarily on the amendment or prioritisation of funding objectives and/or changes in their wording (Jiricka and Pröbstl, 2013 [40]). Again, all of the environmental reports were retrieved from the public access portal for SEA practice (71 reports in December 2015). Table 2 presents the core figures of the analysed SEA related sample, and shows the percentage of plans/progammes included at the local level in comparison to those at superior levels (e.g., regional or national).

Table 2. Strategic environmental assessment (SEA) environmental reports in the survey (SEA database-all 71 available entries).

\begin{tabular}{ccc}
\hline Types of Facility Analysed, SEA & Reports & Percentage \\
\hline Local & 55 & $77.5 \%$ \\
Supralocal & 16 & $22.5 \%$ \\
\hline Total & $\mathbf{7 1}$ & $100 \%$ \\
\hline
\end{tabular}

An equal, regional distribution of Austrian procedures within the sample was not accounted for, because projects and plans (e.g., hydropower, ski facilities ... ) depend on the respective environmental conditions or local needs, which are not equally distributed amongst the Austrian regions [61] (p. 17). 


\subsection{Evaluation Criteria}

The method applied in this study is based on similar approaches. However, due to the high number of documents included in this study, a set of basic criteria that can be easily classified and documented was chosen. The selection of the criteria was influenced by the literature review $[15,29,43,57,65]$ and focusses on the key characteristics of the consideration of alternatives. Furthermore, one aim was the comparison between EIA and SEA as well as the analysis of tiering between them. For this purpose, the criteria that were applied addressed key issues related to tiering: the different type of alternatives (which is important against the background of the alternative hierarchy), the role of the zero-variant as well as the presentation of the results of the consideration of alternatives. For the latter in particular, spatial analysis can play an important role. Outcomes can be more comprehensible by the visual presentation of alternatives. The selected criteria, which are referred to as " $\mathrm{C} 1-5$ " in the following, and their respective background are explained:

Criterion 1-Number of alternatives described in the report (C1): In Austria, as stated in many guidelines for practitioners, an environmental report generally has to present a number of alternatives [66] (p. 39), [47] (p. 46). C1 counts all of the presented alternatives in the report, regardless of the type of alternative, in order to gain an overview of how many alternatives are assessed for the two instruments on average.

There must have been at least a short and comprehensible exposition in the environmental report, allowing a comparison with the relevant contents of the plan, programme, or project in order to be counted as an alternative on its own. The plan or programme itself was generally not counted, save for exceptions in the SEA where the plan/programme itself was questioned as one of a number of scenarios. However, the zero variant was not counted here, but rather treated separately (see C5). This separate treatment of the zero variant is in line with international standards, e.g., [29] (p. 80).

If an environmental report describes a long planning history (sometimes up to decades), the alternatives were counted from the point in time that established a definable start of the final project concept, plan, or programme that was eventually decided on (e.g., through a formulation of objectives, from the corridor survey onwards, after inclusion in the federal roads law, etc.).

Difficulties occurred with alternatives that were obviously not feasible or unrealistic. Those utterly unreasonable "alibi alternatives" (e.g., "inland navigation measures" without the presence of rivers for shipping) were disregarded (and could be found rarely in the total sample).

Criterion 2-Type of alternatives (C2): Based on the literature review and the definitions provided in Section 2.1, the analysis of the SEA and EIA reports in this study focussed on four main different types of alternatives:

\section{- Conceptual alternatives}

- Locational alternatives

- Dimension alternatives

- Technical alternatives

However, the application of this criterion requires again further definitions. Here, the classification of the type of alternative has to be based on the chosen project type or plan. The final version of the project or plan serves as background for the evaluation. Since differentiating between the four types of alternatives can be quite complex, the following Table 3 examples illustrate how the classification was undertaken.

Criterion 3-Statements regarding environmental relevance (impacts) (C3): One required subject of the environmental report is the comparison of the considered alternatives regarding their environmental relevance [47] (p. 47). Therefore, the environmental report should provide a transparent description of the environmental impacts of the possible alternatives. The German Federal Environment Agency [41] (p. 32) states: "Relevant environmental impacts are to be described and evaluated for all alternatives considered during a planning process, not only for the alternative eventually chosen for a given plan or programme". While this aspect is crucial for the international reports $[26,43,67]$, the guidelines 
in Austria provide no common understanding regarding the depth of the evaluation of certain environmental issues, or regarding any specific form or the like. Even a "reason for non-consideration in a few key words" [68] (p. 22) is sufficient, as long as the reason is comprehensible, justified, and environmentally relevant. The evaluation considered only environmentally relevant comments. C3 does not distinguish between a short explanation, or whether a detailed qualitative assessment of the alternatives was provided in the respective environmental report. The evaluation only considered the presentation in the sector on alternatives (and its cross-referenced sectors). Economic or corporate strategy arguments do not count on their own [41], and were not considered in this study.

Table 3. Illustration of classification of types of alternatives through examples.

\begin{tabular}{cl}
\hline Type of Alternative & \multicolumn{1}{c}{ Example for Classification } \\
\hline Conceptual alternative & $\begin{array}{l}\text { Energy Production: A reservoir solution (storage power station: water power) } \\
\text { would constitute a concept alternative to a chosen hydraulic power plant because the } \\
\text { two types of power plant differ in their mode of operation for producing energy. } \\
\text { Transport: Examination of a different means of transport (rail instead of road) is } \\
\text { classified as a concept alternative. The same applies for a road in combination with } \\
\text { other forms of transport (e.g., road along with a strengthening of public transport). }\end{array}$ \\
\hline Dimension alternative & $\begin{array}{l}\text { Energy Production: If different reservoir capacities are evaluated for a hydroelectric } \\
\text { power station, these would be dimension alternatives, since they are related to } \\
\text { different energy potentials of the whole project. } \\
\text { Transport: Alternatives of the total lengths of the traffic route. }\end{array}$ \\
\hline Locational alternative & $\begin{array}{l}\text { Energy Production: Routing the pressure pipeline for a hydroelectric power station } \\
\text { on different slopes of the valley would be locational alternatives, while aboveground } \\
\text { routing of the pipeline vs. underground routing would be counted as a technical } \\
\text { alternative for that power station. }\end{array}$ \\
Transport: Different routes in the existing traffic network constitute \\
locational alternatives.
\end{tabular}

Criterion 4-Presentation/Structuring (C4): The description of alternatives and their possible consequences for the environment and human health in the environmental report are typically presented in written form. However, its information value can be increased significantly if the content is supported by specific illustrations [69] (p. 13). Possible options to illustrate the key findings are plans, maps, diagrams, tables, matrices, figures, aerial photographs, GIS model descriptions (spatial analysis), etc. Therefore, any informative presentation and structuring beyond the use of mere text in addressing the alternatives was rated positively under criterion 4 . As the use of more detailed techniques such as ecological modelling or surveys_as suggested in guidance in other countries [43] —are hardly applied in context of the consideration of alternatives, these are not considered as a sub-criterion.

Criterion 5-Zero variant (C5): Presentation of the zero variant is a mandatory feature of an environmental report, required by European standards and nationally by law [47] (p. 45). The central position ascribed to the zero alternative in the environmental evaluation procedures and its variable expression in practice [29], from the complete absence of a presentation to a discussion of multiple trend alternatives [66] (p. 41), allows the treatment of the zero-alternative to be categorised in the following (see Table 4). 
Table 4. Criteria for evaluation of the zero variant in this study.

\begin{tabular}{|c|c|c|}
\hline \multirow{6}{*}{$\begin{array}{c}\text { Application } \\
\text { Categories }\end{array}$} & \multicolumn{2}{|r|}{ Evaluation Criteria for Zero Variant } \\
\hline & 1 & $\begin{array}{l}\text { The zero variant-in the sense of the likely future development without the plan-is } \\
\text { presented, and the proposed plan is compared and evaluated in relation to it. } \\
\text { Further potential courses of development, eventualities, or time frames are considered } \\
\text { and discussed to outline the problem, and an overall picture is provided for the } \\
\text { proposed project. }\end{array}$ \\
\hline & 2 & $\begin{array}{l}\text { Details on the zero variant-in the sense of the continued development without the } \\
\text { plan-are present. The proposed plan is compared in relation to it, and is discussed } \\
\text { with regard to its environmental relevance, beyond mere simplifying statements. }\end{array}$ \\
\hline & 3 & $\begin{array}{l}\text { Zero variant e is identified. Details on the zero alternative are present-if only } \\
\text { marginally—in that, for example, the continued development in the sense of the zero } \\
\text { alternative corresponds to the current state. }\end{array}$ \\
\hline & 4 & $\begin{array}{l}\text { Details on the zero variant are present, but are not recognised properly as the standard } \\
\text { for evaluation. For example, statements on the need for the proposed plan or on } \\
\text { economic considerations are made, and other irrelevant details are given, but the } \\
\text { environmentally relevant advantages and disadvantages of refraining from pursuing } \\
\text { the plan are not presented. }\end{array}$ \\
\hline & 5 & The zero variant or related details are lacking entirely in the environmental report. \\
\hline
\end{tabular}

\subsection{Limitations}

The presented study does not permit direct conclusions regarding the quality of the integration of the consideration of alternatives in the decision-making process. This is true, especially, for the correct, sufficient, and precise consideration of alternatives, including their environmentally relevant discussions. The number and type of alternatives alone can indicate an adequate treatment on the intended strategic level; however, a final analysis of the benefit of applying different types at different levels (including the outcome at the permitting stage) is still missing. The mere presence of an environmentally relevant exposition of the alternatives in a report does not yet mean that the relevant reasons for selection are interlaced with the environmentally relevant impacts. An additional evaluation of the whole EIA process would be recommended in a future research study, which could reveal whether alternatives were considered continuously during the whole process e.g., in the final commissioning statement and/or led to mitigation respective compensation measures.

\section{Results}

\subsection{Number of Alternatives (C1)}

For the EIA, the study showed that the majority of the documents in Austria comply with the legal obligation to include at least an overview and treatment of considered alternatives. Of the EIA reports that were examined, $80 \%$ provided details on alternatives in a separate chapter. The maximum number of considered alternatives was 25 for a single project. EIS reports with details on considered alternatives dealt with six alternatives on average. Almost half of the EIAs examined contained a description of up to five alternatives (see Figure 1).

A slightly different picture became apparent in the case of the SEA. Almost $40 \%$ of the environmental reports examined contained either no information regarding alternatives (in neither of the chapters), or the information was so inadequate that it was not counted. With approx. five alternatives, an SEA considers somewhat fewer alternatives on average than the examined EIAs. As with the EIA, almost half of the environmental reports examined contained between one and five alternatives. However, the proportion decreases significantly as of the next class (six to 10 alternatives) compared to the EIA (see Figure 2). 


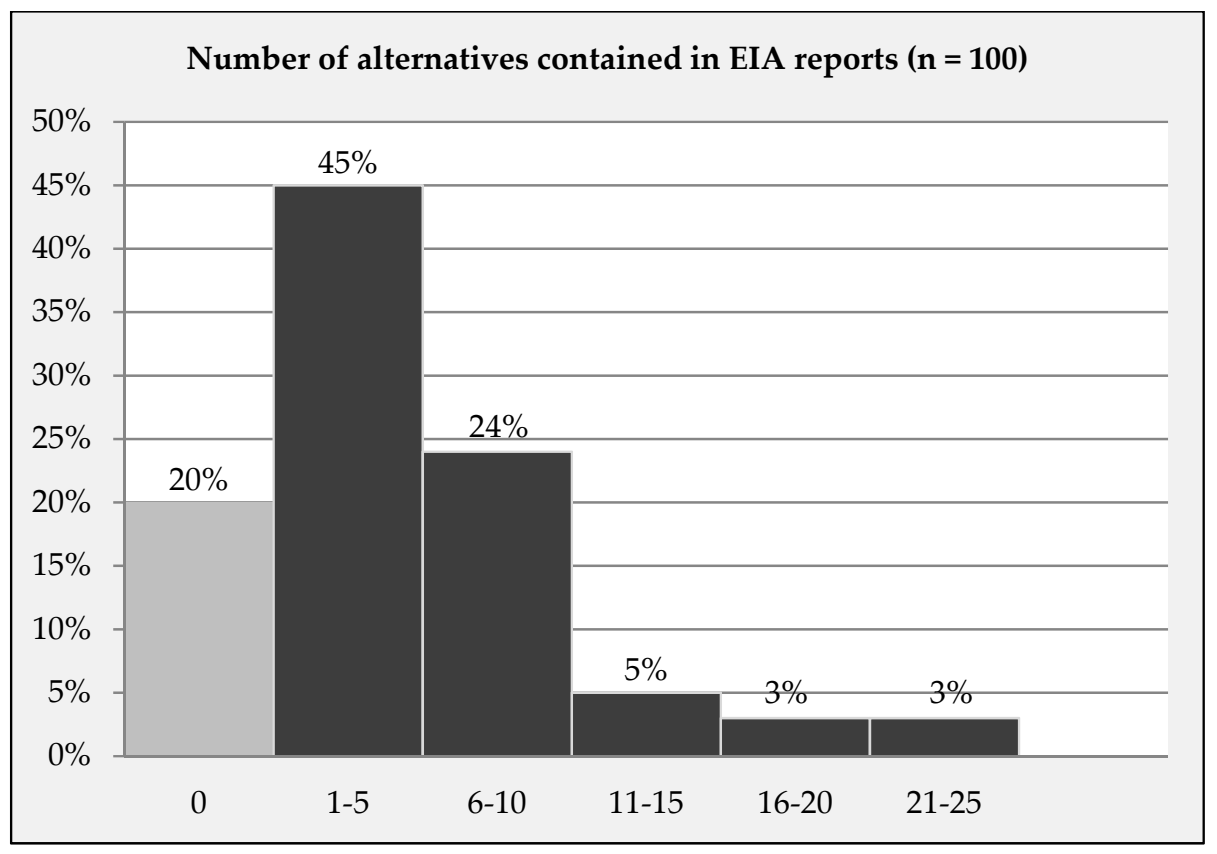

Figure 1. Distribution of numbers of alternatives described per EIA report.

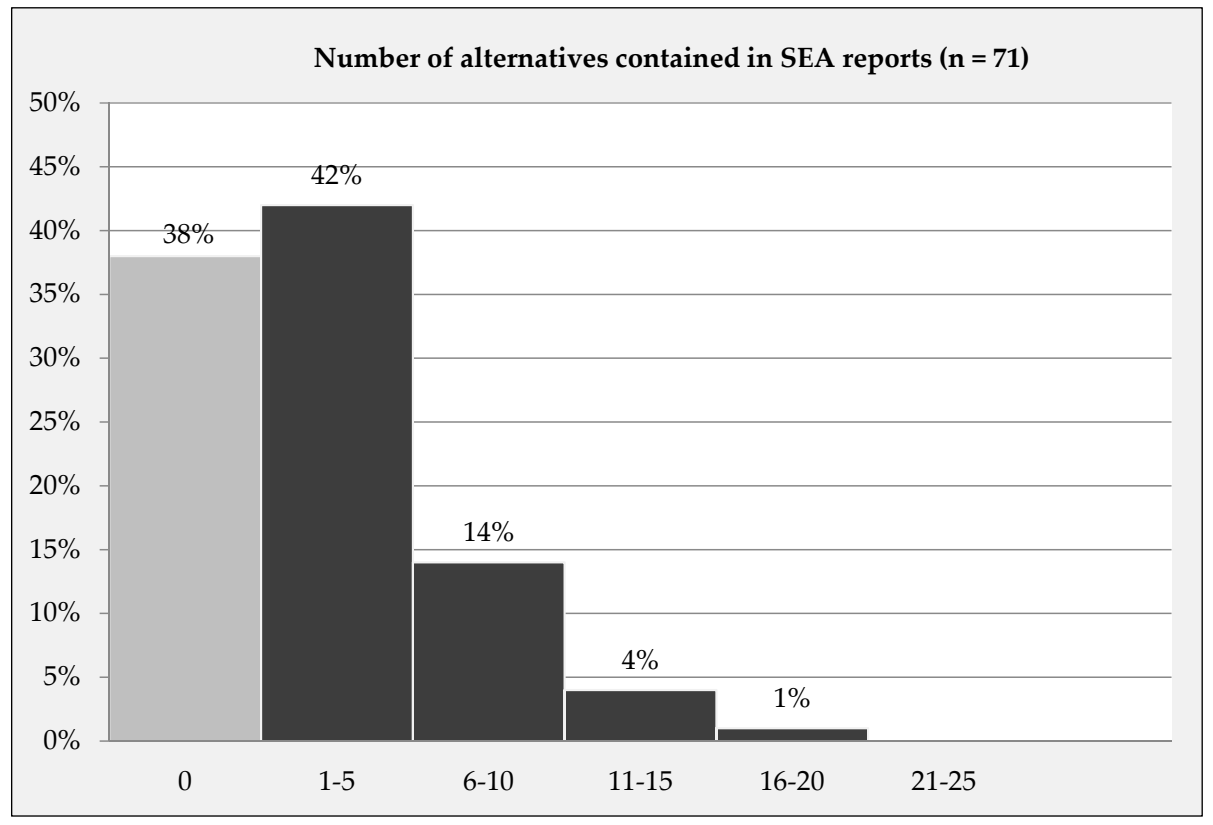

Figure 2. Distribution of number of alternatives described per strategic environmental assessment (SEA) environmental report.

\subsection{Type of Alternatives (C2)}

Regarding the types of alternative considered, the project-oriented focus of the EIA becomes apparent for the consideration of alternatives. Technical alternatives were addressed most (in first position in all of the examined EISs) with approximately $60 \%$ out of all EIS examined. Half of the EIS addressed different locations and a quarter contained dimension alternatives. Concept alternatives were included in $13 \%$ of the reports (see Figure 3); however, all of these were in statements for traffic or hydropower projects. Therefore, the conceptual development of the project therefore mostly involves a consideration of comprehensive traffic aspects or a systematically different mode of operation of a type of power plant. 


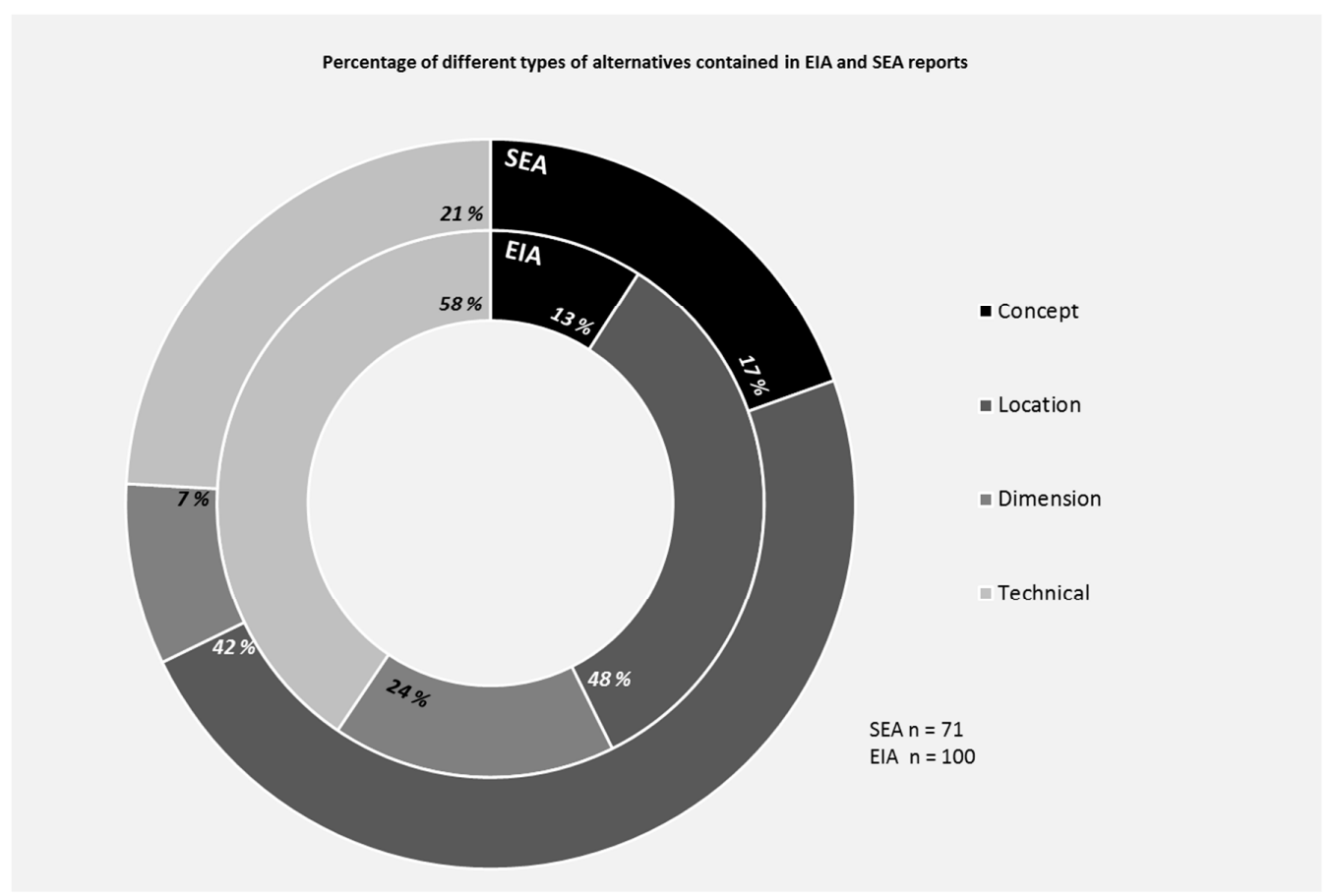

Figure 3. Percentage of different types of alternatives contained in all of the Austrian EIA reports that were examined.

The relevance of the types of alternative in the SEA (see Figure 3) is different to the EIA. Locational alternatives, which were addressed in $42 \%$ of the environmental reports, are in first place, followed by technical alternatives, which were treated in $21 \%$ of environmental reports. Concept alternatives $(17 \%)$ could be found in only $17 \%$ of the environmental reports that were examined. Dimension alternatives are only contained in a minor $10 \%$ of the environmental reports.

Any significant findings regarding differences in EIA and SEA for the use of alternatives depending on the project type were not identified. The number of alternatives and also the type of alternatives are used for all of the projects and plans without specific features.

As outlined in Section 2, both EIA and SEA may consider different types of alternatives in parallel in one report. This is confirmed by the present study. The combination of different types of alternatives within one environmental report can be an indication of multifaceted and multilayered planning. Figure 4 shows the proportion of environmental reports in SEA and EIA containing combinations of one to four of the possible types of alternatives.

In this direct comparison, the EIA shows a greater diversity regarding the combination of types of alternative in Austria. Two-thirds of all of the SEAs addressing alternatives did not contain any combination of types of alternatives. In the case of EIA, on the other hand, more than half of the EISs contained at least one type of alternative. A simple combination of two different types occurred in approximately $30 \%$ of the examined EIA reports, and in $25 \%$ of the examined SEA reports. The same goes for a combination of three different alternatives, which occurred four times as often in the planning and development of alternatives for EIAs as for SEAs (19\% EIA versus 5\% SEA). Upon closer examination of the environmental reports of both instruments that considered three or four different types of alternatives, traffic infrastructure and hydropower projects stand out once more.

\subsection{Statements Regarding Environmental Relevance (C3)}

Strictly speaking, the result of criterion 1 regarding the number of alternatives considered in the instruments would have to be reconsidered in practice, because mere information on alternatives without details regarding their environmental relevance is insufficient. These 'deficiencies' occur in $4 \%$ of environmental reports for the SEA and in $14 \%$ for the EIS of the EIAs that were examined 
(see Figure 5). The consideration of alternatives is based in these cases only on economic reasons and/or a restricted availability of land (e.g., for location alternatives). Another approach is the mere mentioning of alternatives (e.g., locational) without reasoning any of the likely environmental impacts linked to each alternative. As they do not give environmentally relevant details on the alternatives, they do not fulfil the purpose of consideration of alternatives for an environmental impact assessment.

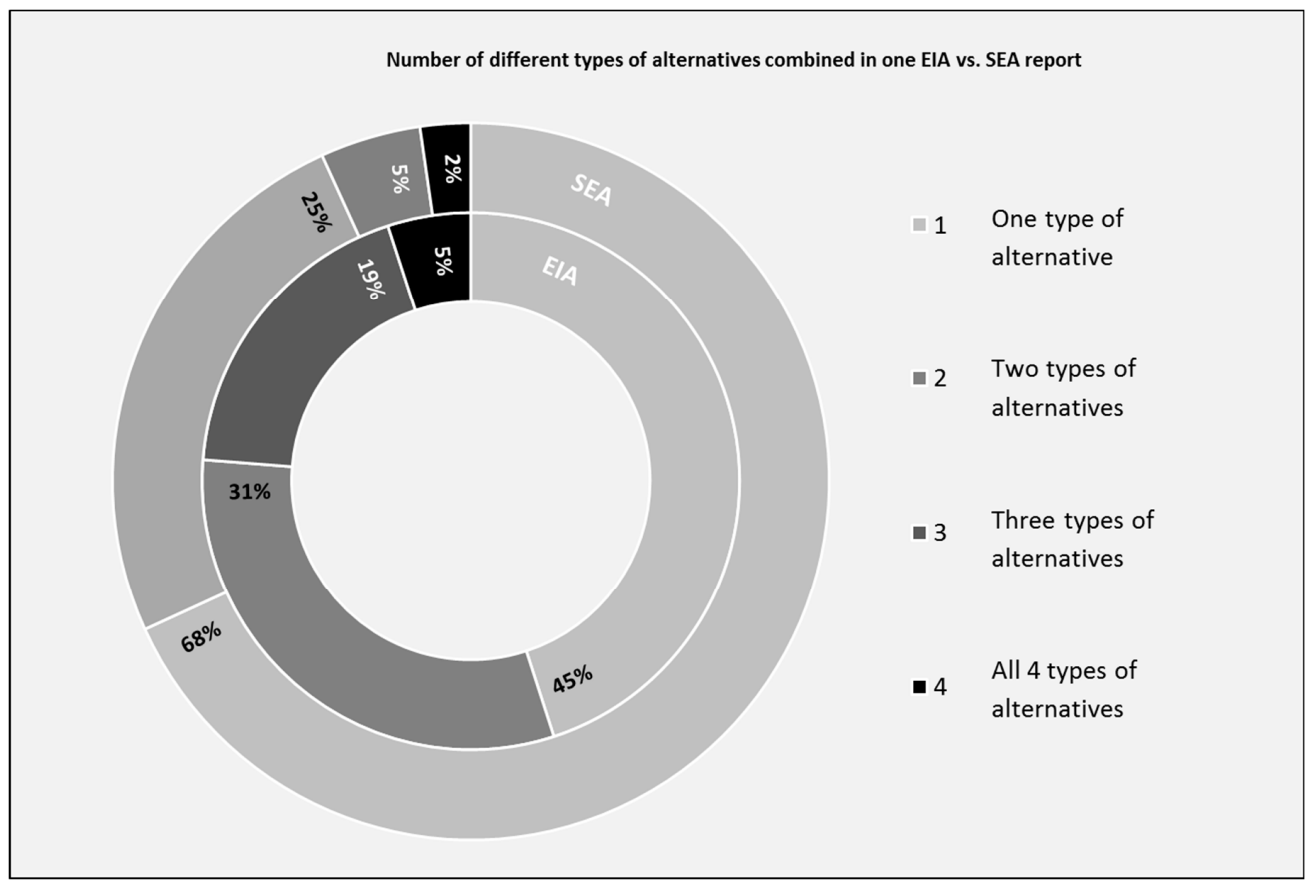

Figure 4. Number of different types of alternatives described in one EIA or SEA report (comparison, EIA: $\mathrm{N}=80$, SEA $\mathrm{N}=44$ ).

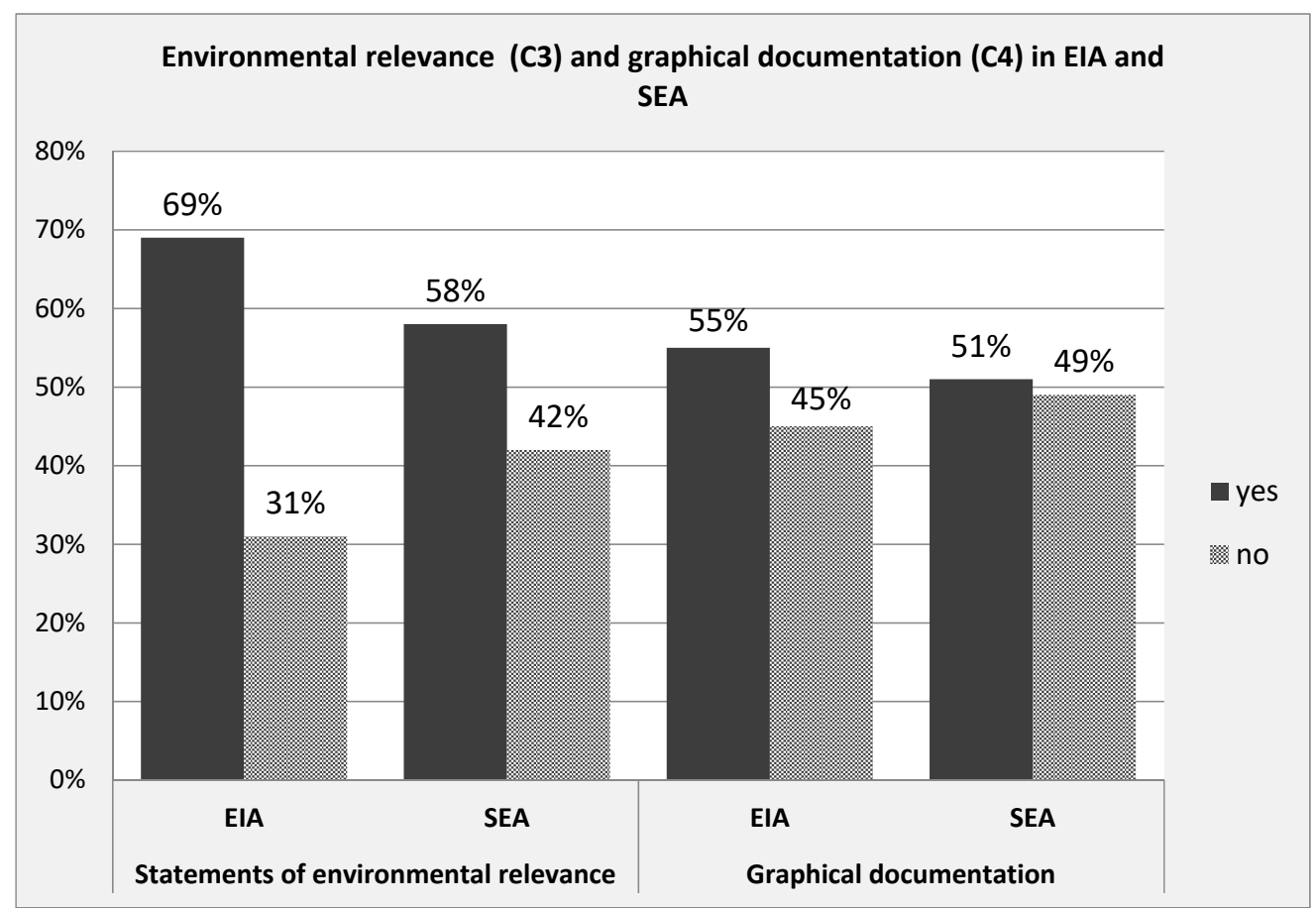

Figure 5. Percentage of statements with environmental relevance/discussion (C3)/graphical documentation (C4). 


\subsection{Presentation and Structuring (C4)}

Graphical documentation and the support of written information thereby on the consideration of alternatives was equally high for both instruments with approximately 55\% for the EIA and approximately $52 \%$ for the SEA. EIAs tend to make more use of plans, maps, and aerial photos, while SEAs make greater use of tables and matrices. This is largely due to the more refined, extensive, and technical EIS with reference to a concrete project, compared to the comparison on a more abstract level conducted by the SEA.

\subsection{Zero Variant (Alternative) (C5)}

In both instruments, EIA and SEA, approximately $10 \%$ of environmental reports disregarded the zero variant entirely (category 5). For the SEA, 14\% of reports made unsuitable use of the zero variant or disrespected its standard for evaluation (category 4). These reports referred mostly to the current state and did not compare the project with the zero variant. Some explained economic interests, which then justified the necessity of the project. This aspect is twice as marked in the case of the EIA, where almost $30 \%$ of the examined EISs fall in this category. The required "minimum approach" regarding use of the zero variant (category 3 ) is followed in both instruments by about $20 \%$ of the reports. While only $36 \%$ of reports fall into categories 1 and 2 in the case of the EIA, it is more than half in the case of the SEA environmental reports. Figure 6 shows the categorised treatment of the zero variant, for EISs and SEA environmental reports. The results show that the description of the zero variant complies with the targets prescribed by guidelines or laws more often in the case of the SEA examined than the EIA.

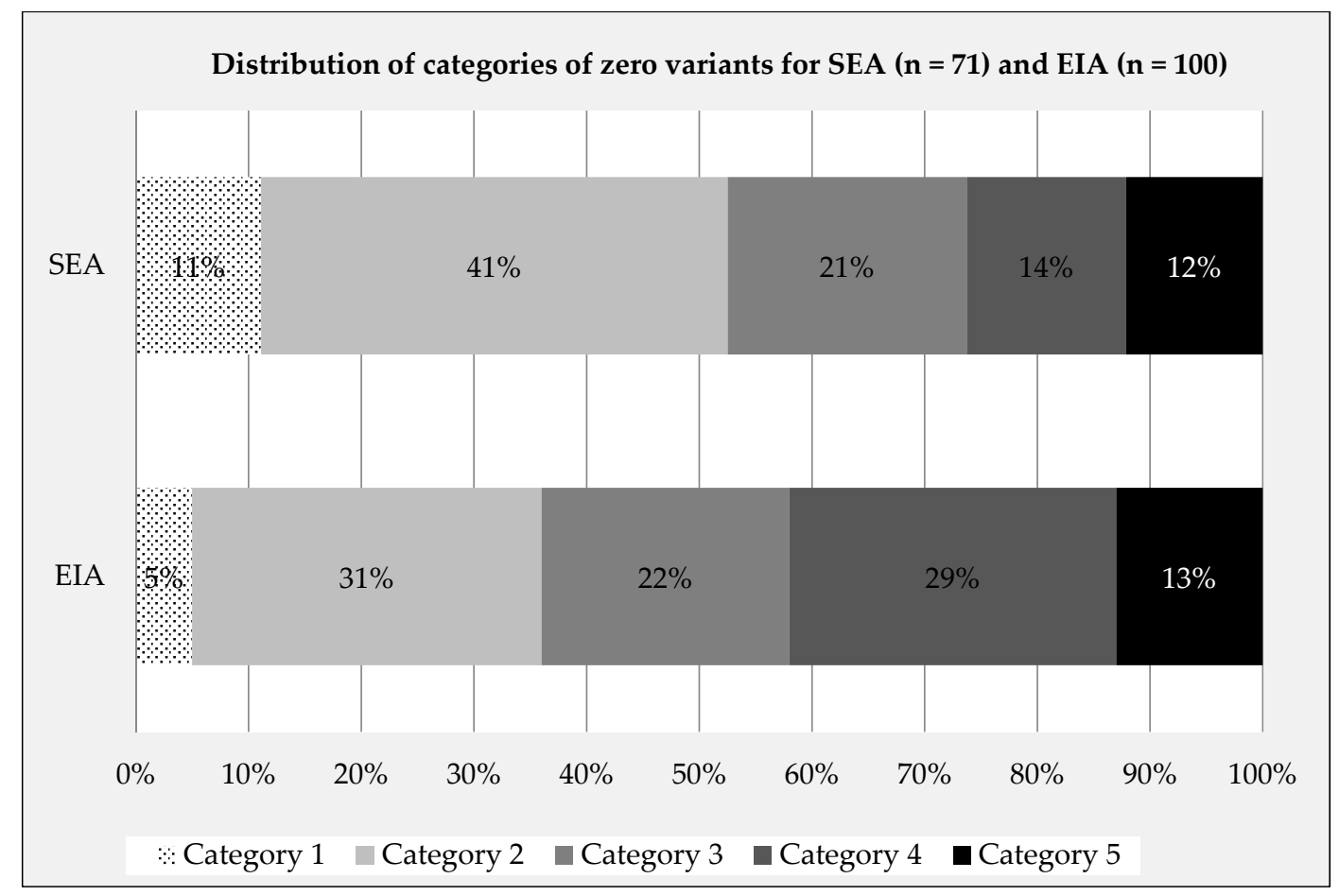

Figure 6. Distribution of categories of zero variants: a comparison of EIA and SEA $(1=$ detailed description, to $5=$ details are entirely lacking).

\section{Discussion}

The two instruments for evaluating environmental impact examined here paint a very heterogeneous picture regarding their "consideration of alternatives". The reflection of the scientific background already revealed uncertainties regarding even clear and consistent definitions, such as for the concept alternatives, for the question of tying the consideration of alternatives to the respective 
evaluation framework, or for the assessment of alternatives ([29] and others). The literature review showed that the definition of alternatives, their implementation into the report, and their transparent description relevant for decision making as well as the consideration of the zero-alternatives have been reason for critical discussion and recommendations. Many of these typical problems are confirmed by this large evaluation of current EIA practice. The statistical-empirical study of SEA and EIA presented here provides a first insight into the application of these two instruments in a large sample.

The study showed that the theoretical approaches of both instruments are reflected in their implementation in the Austrian EIA and SEA practice only partly, which might be influenced by the systems themselves. In the case of the EIA, the presentation of alternatives is largely predetermined by the project applicants and influenced by the approval procedure, which follows the "one-stop-shop" principle of the permitting process. A project planning and conceptualisation pathway with a project-oriented focus is thereby introduced into the EIS. The additional exposition of the environmental relevance of alternatives considered by the project applicants thereby recedes into the background, although this is precisely where the information yield for the evaluation of environmental impacts would be greatest.

For the SEA also, the influence of the Austrian system can be noticed. For the plans of the subject matters considered here, it is less common to step outside of or question the respective objective system. Therefore, depending on the strategic level, the SEA environmental reports are more likely to address the issue of location or different means of technical execution within the framework of the plan or programme. By determining the objectives for which the planning procedure is being undertaken, e.g., zoning for wind turbines or a golf course, the degree of freedom of decision is often already predefined, and the strategic approach of the SEA is faded out to a certain extent. This is confirmed by the critique of Sommer [66] and Stoeglehner [17], but is more a problem of the content and objectives of the planning in Austria, which pose a limitation also to the strategic conceptualisation in the SEA. This application practice was also rightly criticised in the general European study on the effectiveness of the SEA [29].

Looking in detail at the results, it seems to be common practice to incorporate information on alternatives in the environmental reports of EIA ( $80 \%$ contained information on the consideration of alternatives). However, in this respect, it is of particular significance that a high share of the EIA examined (30\%) - despite mentioning alternatives—provides no environmentally relevant details on considered alternatives. In terms of "reasoning (explaining) the choice of the preferred alternatives with regard to their impacts on the environmental issues" (e.g., [43]), these fail one essential part of the consideration of alternatives. This relativises the large number of alternatives considered, since the central aspect of information is lacking in these cases, despite the inclusion of alternatives in the environmental report. A transparent and cooperative evaluation of environmental impacts, which is also in order to achieve higher acceptance during the course of public involvement [70], would need improvement.

Similarly, the result for the SEA must be viewed critically in light of the status regarding the consideration of alternatives assigned to the instrument in theory. Only $62 \%$ of the environmental reports examined in this study included alternatives. Environmental reports-e.g., for local development planning (zoning maps, etc.) - frequently stated that alternatives were considered in the forefront (before the SEA), but were not described in detail due to the large number of variants (regarding changes to the zoning map of a plot in question). It remains to be hoped that this speaks more of a systematic or methodological problem of incorporating them into the environmental reports. However, it shows a clear lack of an iterative process involving the SEA during the planning itself right from the beginning.

The study also provides quantitative insight into the differences regarding the types of alternatives, from which conclusions about the profound and adequate development of alternatives can be inferred. Locational and technical alternatives take a leading role in both EIA and SEA reports. The focus on locational alternatives identified in the SEA is in line with the evaluation of international practise [29] 
(pp. 79-80). The numbers thereby confirm the result of a recently conducted, Europe-wide, qualitative study on SEA [29] (p. 113). The limited use of dimension alternatives in both instruments is surprising, seeing as they would give environmental planners a suitable tool. Another indicative effect is the one-sided or very sparing use of concept alternatives. As Callies and Dross [37] already stated, the formulation of the objective(s) is central in determining the type and characteristic of the alternative. If the efficiency and effectiveness of the consideration of alternatives is to be guaranteed, special focus must be placed on the formulation of objectives and the options to openly question them. This study again confirms the deficiencies identified by the report of the European Commission: "The majority of member states, in fact, opt mainly for assessment of locational or technical alternatives, and focus on changes within a plan or programme rather than changing the objective of the plan. The focus group discussions also concluded that most SEAs do not, in their experience, explicitly compare alternatives, or even develop alternatives, but, rather, react to proposed alternatives. Even when discussed, alternatives are often not strategic, but relate to implementation details" [29] (p. 113). In the EIA reports, concept alternatives were applied almost exclusively in traffic infrastructure and hydropower projects. In the SEA reports, several environmental reports of traffic planning and only a view of spatial planning contained concept alternatives.

Theoretically, the SEA can serve as a frame for the consideration of alternatives in EIAs under the planning scope of the plan/programme (tiering as described e.g., by Jacoby [36] (p. 467)). If so, concept alternatives could be considered at the SEA level already. The combination of types of alternatives would include the superordinated planning levels and could reflect the types of alternatives that already have been considered in these programmes/plans [71]. In the analysed sample, only very few EIA were subject to planning, which underwent an SEA so far. Therefore, this aspect would merit further research in the future.

Compared to the SEA, the EIA stands out through the greater diversity of combinations of different types of alternative in the EIS. However, once again, only a few select project categories actually made use of a combination of different types of alternative energy production (in particular hydropower) and traffic planning. This practise would also offer other sectors potential for a wider consideration of alternatives. In principle, a combination of different types of alternatives within one environmental report or EIS is another aspect that is worthy of further qualitative examination, since this can be an indication of multifaceted and multilayered planning. Continuative qualitative studies are also recommended in this case, especially regarding consideration of alternatives in the decision-making process.

An important further aspect is the way that alternatives are presented. Graphical preparation of the reports on the consideration of alternatives was comparable for both instruments with approximately $55 \%$ for the EIA and approximately 52\% for the SEA. The readability and comprehensibility of a report is significantly increased through such presentation, as also became apparent during the data analysis for this study. Information in reports can not only be conveyed more easily through matrices and other evaluation schemes or graphical aids, they often also allow for a more compressed report volume. The diversity and quality of diagrams would merit further qualitative analysis and international benchmarking.

As a special aspect that is closely related to the consideration of alternatives, the zero variant-a mandatory component in the Austrian EIA system, which is now required by the Directive 2014/52/EU for all member states-was also addressed in this study. The difference between EIA and SEA reports in Austria is indicative for this step of the evaluation. Legally required statements regarding the zero variant are made in the environmental report of the EIA, but they often contain only justifying arguments regarding the necessity of the project, economic considerations, and other irrelevant statements in the Austrian practice. In these (frequent) cases, the reference to the likely development of the environmental issues is not addressed (adequately). Due to its strategical planning orientation, the SEA is less prone to such arguments in the environmental report, as is also confirmed by the present study. 
One central point of critical discussion-similar to criterion three on environmentally relevant details for alternatives-was shown repeatedly during analysis of the Austrian environmental reports. In particular, the EIS contain specific details on the zero variant (mostly within a separate chapter describing the alternatives considered), but when it comes to the actual evaluation of environmental impact, it is almost always the current state that is compared. Only individual specialist fields, especially the field of noise, also establish reference to the zero variant. Even projects that would find a better framework for evaluation by using the zero variant use the current-state nevertheless. Moreover, the zero variant is sometimes also faced with questions of definition in practice. As Gubesch [72] (p. 125) already described, a "fictive zero alternative" can open up in the case of expansion of existing operations with long life spans (e.g., mining projects). Deficiencies regarding the consideration of the zero variant identified in this study can serve as information for those countries, which implement this as a new requirement due to Directive 2014/52/EU. With regard to new environmental aspects such as the consequences of environmental catastrophes with a particular focus on the impacts of climate change (required by the Directive 2014/52/EU), the zero-alternative receives further significance. Jiricka et al. [56], Pröbstl [73], and Fischer [25] showed that this step, in particular, can provide a valuable contribution to the future evaluation and, as the case may be, adaptation. Not only in this context can the scoping help to identify possible types of alternatives.

\section{Conclusions and Outlook}

The theoretical evaluation that was discussed in this article presents an insight into the practice of the assessment of alternatives and serves as clarification of the systematic position of the consideration of alternatives. Deficiencies identified empirically by the quantitative examination of a large number of EIS and environmental reports in this study are not in the majority linked to the Austrian EIA and SEA system, but support findings of previous studies such as Geneletti [16] or Phylip-Jones and Fischer [11]. In particular, the low environmental relevance of the alternative assessment presented in the evaluated EIS and environmental reports as well as the lack of linking the zero variant to the future development of the environmental issues shows a strong need for improvement. The examination framework must be clearly outlined and objectives specified, so that the difference between the pre-planning and project framework and the actual alternatives - which are considered according to their environmental relevance-is clear and transparent. To this aim, also the scoping should help to identify and lay down possible alternatives, which later on can be addressed against the background of the environmental information gained during the zero variant and impact assessment of the environmental issues. In particular for the SEA, this would guarantee a complete consideration of the environmental impacts that are associated with the respective alternative. In this context, the variety of types of alternatives is of importance, too. Again, an improvement-in particular for the SEA-is deemed to be necessary. Furthermore, in relation to this aspect, the zero variant-which was recently required also for EIA reports by Directive 2014/52/EU for all member states-should receive significantly more attention.

In any case, scientific revision of the topic of consideration of alternatives is still far from complete. The large analysis conducted here would profit from an additional analysis of the impact of the consideration of alternatives on the decision-making phase as well as a repeated detailed look at tiering between the two SEA and EIA instruments when enough SEA are completed, which would allow a thorough analysis of the application of an alternative hierarchy.

Author Contributions: Conceptualization, U.P.-H. and A.J.-P.; Methodology, all three authors; Formal Analysis, M.B. and A.J.-P.; Investigation, M.B.; Resources, M.B.; Data Curation, M.B.; Writing-Original Draft Preparation, A.J.-P., M.B.; Writing-Review \& Editing, A.J.-P. and U.P.-H.; Visualization, M.B. and A.J.-P.; Supervision, U.P.-H.; Project Administration, M.B.

Funding: This research was funded by BOKU Vienna Open Access Publishing Fund.

Conflicts of Interest: The authors declare no conflict of interest. 


\section{References}

1. Petts, J. Public participation and environmental impact assessment. In Handbook of Environmental Impact Assessment, Environmental Impact Assessment: Process, Methods and Potential; Petts, J., Ed.; Blackwell: Oxford, UK, 1999; Volume 1, pp. 145-177.

2. Wood, C. Environmental impact assessment in developing countries. Int. Dev. Plan. Rev. 2003, 25, 301-321. [CrossRef]

3. Busse, J.; Dirnberger, F.; Pröbstl-Haider, U.; Schmid, W. Die Umweltprüfung in der Gemeinde-Mit Ökokonto, Umweltbericht, Artenschutzrecht, Energieplanung und Refinanzierung; Rehm Verlag: Heidelberg, Germany, 2013.

4. Jay, S.; Jones, C.; Slinn, P.; Wood, C. Environmental impact assessment: Retrospect and prospect. Environ. Impact Assess. Rev. 2007, 27, 287-300. [CrossRef]

5. Wende, W. EIA research in Germany. J. Impact Assess. Proj. Apprais. 2002, 20, 93-99. [CrossRef]

6. Sadler, B. Environmental Assessment in a Changing World: Evaluating Practice to Improve Performance. In International Study of the Effectiveness of Environmental Assessment; International Association for Impact Assessment: Toronto, ON, Canada, 1996; ISBN 0-662-24702-7.

7. Wood, C. Comparative evaluation of environmental impact assessment systems. In Handbook of Environmental Impact Assessment, Environmental Impact Assessment in Practice: Impact and Limitations; Petts, J., Ed.; Blackwell: Oxford, UK, 1999; Volume 2, pp. 10-34.

8. Ahmad, B.; Wood, C. A comparative evaluation of the EIA systems in Egypt, Turkey and Tunisia. Environ. Impact Assess. Rev. 2002, 22, 213-234. [CrossRef]

9. Bassi, A.; Howard, R.; Geneletti, D.; Ferrari, S. UK and Italian EIA systems: A comparative study on management practice and performance in the construction industry. Environ. Impact Assess. Rev. 2012, 34, 1-11. [CrossRef]

10. Phylip-Jones, J.; Fischer, T.B. EIA for Wind Farms in the United Kingdom and Germany. J. Environ. Assess. Policy Manag. 2013, 15. [CrossRef]

11. Phylip-Jones, J.; Fischer, T. Strategic environmental assessment (SEA) for wind energy planning: Lessons from the United Kingdom and Germany. Environ. Impact Assess. Rev. 2015, 50, 203-212. [CrossRef]

12. Desmond, M. Decision criteria for the identification of alternatives in strategic environmental assessment. Impact Assess. Proj. Apprais. 2007, 25, 259-269. [CrossRef]

13. Jiricka, A.; Pröbstl, U. One common way-The strategic and methodological influence on environmental planning across Europe. Environ. Impact Assess. Rev. 2009, 29, 379-389. [CrossRef]

14. Köppel, J.; Peters, W.; Wende, W. Eingriffsregelung Umweltverträglichkeitsprüfung FFH-Verträglichkeitsprüfung; Ulmer: Stuttgart, Germany, 2004.

15. Rehausen, A.; Albrecht, J.; Geissler, G.; Hoppenstedt, A.; Köppel, J.; Magel, I.; Scholles, F.; Stemmer, B.; Syrbe, R.U.; Wende, W. SUP-Qualitätskriterien: Ansprüche an eine Strategische Umweltprüfung. In UVP-Report; UVP: Paderborn, Germany, 2015; Volume 29, pp. 96-103. Available online: https://www.researchgate.net/publication/281932897_SUP-Qualitatskriterien_Anspruche_an_ eine_Strategische_Umweltprufung (accessed on 7 April 2016).

16. Geneletti, D. Integration of impact assessment types improves consideration of alternatives. Impact Assess. Proj. Apprais. 2014, 32, 17-18. [CrossRef]

17. Stoeglehner, G. Enhancing SEA effectiveness: Lessons learnt from Austria experiences in spatial planning. Impact Assess. Proj. Apprais. 2010, 28, 217-231. [CrossRef]

18. Fischer, T.B.; Matuzzi, M.; Nowacki, J. The consideration of health in strategic environmental assessment (SEA). Environ. Impact Assess. Rev. 2010, 30, 200-210. [CrossRef]

19. Kontic, B. Effects of the revised EIA Directive on practice in Slovenia. In UVP-Report; UVP: Paderborn, Germany, 2016; Volume 30, pp. 101-105. Available online: http://uvp.de/de/uvp-report/jg30/jg30h2 (accessed on 12 September 2016).

20. Fischer, T.B. Strategic environmental assessment in post-modern times. Environ. Impact Assess. Rev. 2003, 23, 155-170. [CrossRef]

21. Bina, O. A critical review of the dominant lines of argumentation on the need for strategic environmental assessment. Environ. Impact Assess. Rev. 2007, 27, 586-606. [CrossRef]

22. Bram, N.; Nwanekezie, K. Conceptualizing Strategic Environmental Assessment: Principles, Approaches and Research Directions. Environ. Impact Assess. Rev. 2017, 62, 165-173. 
23. Cashmore, M.; Gwilliam, R.; Morgan, R.; Cobb, D.; Bond, A. The interminable issue of effectiveness: Substantive purposes, outcomes and research challenges in the advancement of environmental impact assessment theory. Impact Assess. Proj. Apprais 2004, 22, 295-310. [CrossRef]

24. EIA Directive-Directive 2014/52/EU of the European Parliament and of the Council of 16 April 2014 amending Directive 2011/92/EU on the assessment of the effects of certain public and private projects on the environment. Off. J. Eur. Union L 2014, 124, 1-18.

25. Fischer, T. Implications of the revised EIA Directive. In UVP Report; UVP: Paderborn, Germany, 2016; Volume 30, pp. 59-60. [CrossRef]

26. Köppel, J. Wishful thinking on the potential of the amended EU Directive 2014 for reviving EIA in Germany? In UVP-Report; UVP: Paderborn, Germany, 2016; Volume 30, pp. 61-62. Available online: www.uvp.de/de/ uvp-report/jg30/jg30h2 (accessed on 12 September 2016).

27. Geneletti, D. Some considerations on the potential implications of the revised EIA Directive for Italy. In UVP-Report; UVP: Paderborn, Germany, 2016; Volume 30, pp. 63-64. Available online: www.uvp.de/de/ uvp-report/jg30/jg30h2 (accessed on 12 September 2016).

28. Khoskhkar, S.; Hörnberg, C.; Lundberg, K.; Balfors, B. Focus on biodiversity in the amended EIA Directive-Swedish perspectives. In UVP-Report; UVP: Paderborn, Germany, 2016; Volume 30, pp. 65-670.

29. European Commission. Study Concerning the Preparation of the Report on the Application and Effectiveness of the SEA Directive (Directive 2001/42/EC); Banfi, P., Hernandez, G., Lukacova, Z., Mc Guinn, J., Mc Neill, A., Sweeney, L., Eds.; EC: Brussels, Belgium, 2016.

30. SEA Directive-Directive 2001/42/EC of the European Parliament and of the Council of 27 June 2011 on the assessment of the effects of certain plans and programmes on the environment. Off. J. Eur. Union L 2011, 197, 30.

31. Mc Cold, L.N.; Saulsbury, J.W. Defining the no-action alternative for national environmental policy act analyses of continuing actions. Environ. Impact Assess. Rev. 1998, 18, 15-37. [CrossRef]

32. Arts, J.; Runhaar, H.; Fischer, T.; Jha-Thakur, U.; Van Laerhoven, F.; Driessen, P.; Onyango, V. The effectiveness of EIA as an instrument for environmental governance: Reflecting on 25 years of EIA practice in the Netherlands and the UK. J. Environ. Assess. Policy Manag. 2012, 14. [CrossRef]

33. Steinemann, A. Improving alternatives for environmental impact assessment. Environ. Impact Assess. Rev. 2001, 21, 3-21. [CrossRef]

34. Tickner, J.A.; Geiser, K. The precautionary principle stimulus for solution- and alternatives-based environmental policy. Environ. Impact Assess. Rev. 2004, 24, 801-824. [CrossRef]

35. Enserink, B. A quick scan for infrastructure planning: Screening alternatives through interactive stakeholder analysis. Impact Assess. Proj. Apprais. 2000, 18, 15-22. [CrossRef]

36. Jacoby, C. Die Strategische Umweltprüfung in der Raumplanung. Instrumente, Methoden und Rechtsgrundlagen für die Bewertung von Standortalternativen in der Stadt- und Regionalplanung; Erich Schmidt: Berlin, Germany, 2000; p. 355.

37. Callies, C.; Dross, M. Alternativenprüfung im Kontext des Netzausbaus-Überlegungen im Blick auf die Strategische Umweltprüfung des Bundesbedarfsplans Übertragungsnetze. Z. F. Umweltr. 2013, 2, 76-81.

38. Geißler, G.; Rehhausen, A. Wie strategisch ist die Strategische Umweltprüfung (SUP)? Zur SUP-Anwendung in Deutschland und den USA. In UVP-Report; UVP: Paderborn, Germany, 2014; Volume 28, pp. 119-127.

39. Fischer, T.B.; Gazzola, P. SEA effectiveness criteria-equally valid in all countries? The case of Italy. Environ. Impact Assess. Rev. 2006, 26, 396-409. [CrossRef]

40. Jiricka, A.; Probstl, U. The role of SEA in integrating and balancing high policy objectives in European cohesion funding programmes. Environ. Impact Assess. 2013, 38, 44-53. [CrossRef]

41. Balla, S.; Peters, H.J.; Wulfert, K. Guidance on Strategic Environmental Assessment (SEA) According to the Federal German Act on Environmental Impact Assessment (EIA Act); German Environment Agency/Umweltbundesamt: Dessau-Rosslau, Germany, 2008. Available online: www.umweltbundesamt.de/sites/default/files/medien/ publikation/long/3746.pdf (accessed on 12 September 2016).

42. Heidemann, M. Die Alternativenprüfung bei Planungsentscheidungen. Univ. Diss. Hamburg. In Europäische Hochschulschriften Reihe II Rechtswissenschaft Bd. 5343; Peter Lang: Frankfurt am Main, Germany, 2012.

43. Gonzalez, A.; Therivel, R.; Fry, J.; Foley, W. Developing and assessing alternatives in Strategic Environmental Assessment. In 157 EPA Research Report; Environmental Protection Agency: Wexford, Ireland, 2015; ISBN 978-1-84095-603-0. 
44. Scholles, F.; Scholz, J. Alternativenprüfung und Monitoring. Methodische Hinweise für neue Aufgaben. In Die Strategische Umweltprüfung (SUP) in der örtlichen Raumplanung-Anspruch und Wirklichkeit; Pröbstl, U., Weber, G., Stöglehner, G., und Jiricka, A., Eds.; Eigenverlag: Vienna, Austria, 2007; pp. 16-17.

45. Friedrichsen, L. Umweltbelastende Vorhaben und Alternativen in der Planfeststellung. In Schriften zum Deutschen und EuropäIschen öFfentlichen Recht, 1st ed.; Detterbeck, S., Ed.; Peter Lang GmbH, Internationaler Verlag der Wissenschaften: Frankfurt am Main, Germany, 2005; ISBN 3631538855.

46. Opinion of Advocate General Kokott C-441/03; Commission/Netherlands, EU: Dordrecht, The Netherlands, 2005; Para. 17; p. 80.

47. Environment Agency Austria. UVE-Leitfaden. Eine Information zur Umweltverträglichkeitserklärung. Überarbeitete Fassung 2012; Umweltbundesamt Gmbh: Vienna, Austria, 2012; ISBN 978-3-99004-199-4.

48. Greory, R.; Keeney, R.L. Creating Policy Alternatives Using Stakeholder Values. Manag. Sci. 1994, 40, 1035-1048. [CrossRef]

49. Brownlie, S. Planning Guideline for Involving Biodiversity, Specialists in Eia Processes, Draft for Comment, 1st ed.; CSIR Report No ENV-S-C 2005053 C: Cape Town, South Africa, 2005.

50. European Commission. Guidance on EIA. Scoping. Generaldirektion Umwelt. 2001. Available online: http:/ / ec.europa.eu/environment/eia/eia-support.htm (accessed on 12 September 2016).

51. European Commission Environment. Umsetzung der Richtlinie 2001/42/EG des Europäischen Parlaments und des Rates über die Prüfung der Umweltauswirkungen bestimmter Pläne und Programme. Leitfaden der Europäischen Kommission, GD Umwelt. 70 Seiten; EC: Brussels, Belgium, 2001.

52. Khakzadeh-Leiler, L. SUP und UVP: Verflechtung und Abgrenzung. In UVP-Verfahren vor dem Umweltsenat; Ennöckl, D., Raschauer, N., Eds.; Verlag Österreich: Wien, Austria, 2008.

53. Bergthaler, W.; Niederhuber, M.; Klaffl, I.; Brandl, K.; Kurzweil, A.; Leitner, M.; Lexer, W.; Margelik, E.; Nagl, C.; Tulipan, M. UVP-EVALUATION Evaluation der Umweltverträglichkeitsprüfung in Österreich; Environment Agency Austria: Vienna, Austria, 2006; ISBN 3-85457-834-2. Available online: www. umweltbundesamt.at/fileadmin/site/publikationen/REP0036.pdf (accessed on 18 April 2016).

54. Stoeglehner, G.; Wegerer, G. The SEA-Directive and the SEA-protocol adopted to spatial planning-similarities and differences. Environ. Impact Assess. Rev. 2008, 26, 586-599. [CrossRef]

55. Pröbstl, U.; Jiricka, A.; Stöglehner, G. Die SUP-Umsetzung in der örtlichen Raumordnung in Österreich. In UVP-Report; UVP: Paderborn, Germany, 2006; Volume 20, pp. 52-55.

56. European Commission. Bericht der Kommission an das Europäische Parlament und den Rat über die Anwendung und den Nutzeffekt der UVP-Richtlinie (Richtlinie 85/337/EWG, in der Fassung der Richtlinie 97/11/EG); Die Erfolge der Mitgliedstaaten bei der Umsetzung der UVP-Richtlinie, KOM(2003) 334 endgültig vom 23.06.2003; EC: Brussels, Belgium, 2003.

57. Jiricka, A.; Bösch, M.; Völler, S. Learning from the past and upcoming challenges-The implementation of the amendment of the EIA Directive in Austria. In UVP-Report; UVP: Paderborn, Germany, 2016; Volume 30, pp. 143-151.

58. Hecht, M.; Walcher, A.; Poecheim, M. Die Alternativenprüfung in der NVP und UVP bei Verkehrsinfrastrukturprojekten. Recht Der Umw. 2007, 90, 184-191.

59. Bräuer, V. Die Genehmigung der 380-kV-Salzburgleitung. Erdverkabelung versus Freileitung. Recht Der Umw. 2011, 49, 91-98.

60. Arbter, K. SUP Strategische Umweltprüfung für die Planungspraxis der Zukunft. SUP-Erfolgsfaktoren, aktuelle Trends und zukunftsweisende Entwicklungen der SUP, 2nd ed.; Neuer wissenschaftlicher Verlag: Wien, Graz, Austria, 2007.

61. Bmlfuw. 6. UVP-Bericht an den Nationalrat 2015. Bericht des BMLFUW an den Nationalrat gemäß § 44 UVP-G 2000 über die Vollziehung der Umweltverträglichkeitsprüfung in Österreich; Bundesministerium für Nachhaltigkeit und Tourismus: Wien, Austria, 2015.

62. Schmidt, M.; Joao, E.; Albrecht, E. (Eds.) Implementing Strategic Environmental Assessment; Springer: Berlin, Germany, 2004.

63. Fischer, T. Strategic Environmental Planning in Transport and Land Use Planning; Earthscan: London, UK, 2002.

64. EIA Act 2000. Bundesgesetz über die Prüfung der Umweltverträglichkeit (Umweltverträglichkeitsprüfungsgesetz 2000_UVP-G 2000); BGBl. 697/1993, last change BGBl. I Nr. 4/2016; Bundesgesetzblatt (BGBl): Bonn, Germany, 2016. 
65. Posas, P. Climate change in SEA: Learning from English local spatial planning experience. Impact Assess. Proj. Apprais. 2011, 29, 289-302. [CrossRef]

66. Sommer, A. Strategische Umweltprüfung: Vom Untersuchungsrahmen zur Erfolgskontrolle. Inhaltliche Anforderungen und Vorschläge für die Praxis; Bmlfuw: Vienna, Austria, 2005.

67. Kaule, G. Umweltplanung und Biodiversität: Implikationen für die Politik. In Messung und Ökonomische Bewertung von Biodiversität: Mission Impossible; Wismann, J., Hoffmann, A., Hoffmann, S., Eds.; Metropolis-Verlag: Marburg, Germany, 2003; pp. 179-203.

68. Ktn. LReg. Die Strategische Umweltprüfung (SUP) in Kärnten. SUP Leitfaden für die örtliche Raumplanung; Amt der Kärntner Landesregierung: Klagenfurt am Wörthersee, Austria, 2007.

69. Bmlfuw. SUP-Praxisblatt 4; Alternativenprïfung in der SUP; Ergebnisse des SUP-Arbeitskreises vom 2.12.2014; Bmlfuw: Wien, Austria, 2015.

70. Dietrich, B.; Au, C.; Dreher, J. Umweltrecht der Europäischen Gemeinschaften. Institutionen, Entwicklung und Ziele; Erich Schmidt Verlag: Berlin, Germany, 2003.

71. Fischer, T. Reviewing the quality of strategic environmental assessment reports for English spatial plan core strategies. Environ. Impact Assess. Rev. 2010, 30, 62-69. [CrossRef]

72. Gubesch, V. Einkaufszentren im Umweltrecht. Ausgewählte Rechtsprobleme des UVP-Genehmigungsverfahrens, aufgezeigt anhand zweier Fallstudien zu Genehmigungsverfahren für Einkaufszentren mit und ohne UVP-Pflicht. Ph.D. Thesis, Universität Wien, Vienna, Austria, 2013.

73. Pröbstl-Haider, U. Berücksichtigung des Klimawandels bei kommunaler Planung und im Umweltbericht. In UVP-Report; UVP: Paderborn, Germany, 2014; Volume 28, pp. 14-17, ISSN 0933-0690.

(C) 2018 by the authors. Licensee MDPI, Basel, Switzerland. This article is an open access article distributed under the terms and conditions of the Creative Commons Attribution (CC BY) license (http:/ / creativecommons.org/licenses/by/4.0/). 